\title{
Second-order polarizability of donor-acceptor substituted oligothiophenes: substituent variation and conjugation length dependence
}

\author{
Frank Würthner, Franz Effenberger \\ Institut für Organische Chemie der Universität Stuttgart, Pfaffenwaldring 55, W-7000 Stuttgart 80, Germany \\ Rüdiger Wortmann and Peter Krämer \\ Institut für Physikalische Chemie der Universität Mainz, Jakob Welder-Weg 11, W-6500 Mainz, Germany
}

Received 3 December 1992

\begin{abstract}
Second-order polarizabilities and excited state dipole moments of a number of donor-acceptor substituted $\alpha$-oligothiophenes have been investigated by use of electric field induced second harmonic generation (EFISH), solvatochromism and electrooptical absorption measurements (EOAM). The experimental results reveal that oligothiophenes are very effective conjugation units offering substantial enhancement of the second-order polarizability with increasing chain length.
\end{abstract}

\section{Introduction}

Conjugated organic molecules exhibit interesting physical and chemical properties, both from the fundamental point of view and for their application in data processing $[1,2]$. In recent years we have studied the photophysical properties of donor-acceptor substituted conjugated molecules [3]. As model systems we used polyenes as did others [4] because polyenes possess the greatest effective conjugation length. However, for the application the thermal and (photo)chemical stability of polyenes seem to be inadequate. More stable compounds which also exhibit extended conjugation are $\alpha$-linked oligothiophenes $[5,6]$. For thiophene oligomers and polymers the application in electronic devices has already been demonstrated $[7,8]$. Indeed most work previously done has been focused on unsubstituted or alkyl substituted systems.

For an attractive application in nonlinear optics, however, such as for example frequency doubling or electrooptic modulation of light, donor-acceptor substituted conjugated molecules which exhibit charge dissymmetry, are required.

Systematic investigations of structure-property re- lations of many donor-acceptor substituted organic $\pi$ systems and their molecular second-order polarizabilities $\beta$ have been carried out, e.g. benzenes, oligophenylenes, phenylpolyenes and diphenylpolyenes [4,9-15]. The largest values for second-order polarizabilities $\beta$ have been obtained for long-chain polyenes containing amine donor and nitro or formyl acceptor groups [4,11-14]. For the oligophenylene series, in contrast, phenyl extension beyond the terphenyl is not worthwhile because of the rapid saturation of $\beta[14,15]$.

Concerning thiophenes only few experimental data on second-order polarizabilities of some thiophenephenylene systems exist $[14,16]$. So we synthesized a number of donor-acceptor substituted $\alpha$-oligothiophenes $\mathrm{DT}_{n} \mathrm{~A}$ to investigate systematically the second-order polarizability of thiophene oligomers [17].

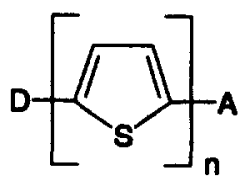

Scheme 1. Donor: $\mathrm{D}=\mathrm{MeO}, \mathrm{MeS}, \mathrm{Me}_{2} \mathrm{~N}, \mathrm{PyN}$. Acceptor: $A=\mathrm{NO}_{2}, \mathrm{CHO} . n=1-4$. 
Electron-donating substituents are methoxy, methylthio, dimethylamino and pyrrolidino (PyN) while the nitro and formyl groups are used as acceptor substituents. Second-order polarizabilities as well as ground and excited state dipole moments of these compounds were determined by means of electricfield induced second harmonic generation (EFISH) [18], solvatochromism $[19,20]$ and electrooptical absorption measurements (EOAM) $[21,22]$. From the change of the dipole moment upon electronic excitation we estimate the charge transfer contribution of the lowest excited singlet state to the second-order polarizability using the two-state approximation [23].

\section{Experimental section}

All new compounds gave correct elemental analysès and spectral ' properties ( ${ }^{1} \mathrm{H}-\mathrm{NMR},{ }^{13} \mathrm{C}-\mathrm{NMR}$, IR) in agreement with the assigned structures. 2-Methoxy-5-nitro-thiophene was prepared according to Sicé [24].

Absorption spectra were obtained in the range 200$800 \mathrm{~nm}$ using a Perkin-Elmer Lambda 7 spectrometer. The molar extinction coefficient $\kappa$ was determined for $n$-hexane solutions applying the LambertBeer equation. For the solvatochromic determinations we used dried Merck Uvasol solvents.

The ground state dipole moments have been determined from dielectric measurements at $2 \mathrm{MHz}$ using a WTM-DM 01 dipole meter and from refractive measurements for $\mathrm{Na}_{D}$ light using a Milton Roy Abbe$3 \mathrm{~L}$ refractometer. The dipole meter scale readings were calibrated and converted to dielectric constants by the'use of $n$-pentane, $n$-hexane, cyclohexane, benzene and toluehe as reference liquids. For each cómpound we measured $4-6$ benzenic solutions at $20^{\circ} \mathrm{C}$ over the concentration range of the solute from $2 \times 10^{-4}$ to $2 \times 10^{-2} \mathrm{~mol} / \ell$.

All nitro substituted compounds exhibiting sufficient solubility in apolar solvents and showing no or negligible absorption at $532 \mathrm{~nm}$ were investigated by means of the EFISH technique [18]. Details of the device used in this work will be published elsewhere [25]. The EFISH results are relative to quartz $\left(d_{11}=0.5 \mathrm{pm} / \mathrm{V}[26]\right)$. The caltbration was made under the same focal conditions as the solution mea- surements, the quartz reference crystal being placed in the liquid cell volume and immersed in an index matching liquid. The mass fraction of the solution measurements was typically in the range $0-10^{-3}$.

The electrooptical absorption apparatus has been described in ref. [27]. The solvents used in EFISH, dielectric and EOA measurements, cyclohexane, methylcyclohexane, tetrachloromethane, benzene and toluene were carefully dried and purified by rectification.

\section{Theory}

In many organic molecules of donor-acceptor type virtual transitions to the lowest excited singlet state ("charge transfer state") give the main contribution to the second-order polarizability $\beta[23,28]$. The charge transfer contribution can be written in the form

$$
\begin{aligned}
& \beta_{\mathrm{CT}}(\tilde{\nu})=\beta_{0} \frac{\tilde{\nu}_{\mathrm{az}}^{4}}{\left(\tilde{\nu}_{\mathrm{ag}}^{2}-\tilde{\nu}^{2}\right)\left(\tilde{\nu}_{\mathrm{ag}}^{2}-4 \tilde{\nu}^{2}\right)}, \\
& \beta_{0}=\frac{3}{2 h^{2} c_{0}^{2}} \mu_{\mathrm{ag}}^{2}\left(\mu_{\mathrm{a}}-\mu_{\mathrm{g}}\right) \frac{1}{\tilde{\nu}_{\mathrm{ag}}^{2}},
\end{aligned}
$$

where $\beta_{0}$ is the static second-order polarizability, $\mu_{\mathrm{g}}$ and $\mu_{\mathrm{a}}$ are ground and excited state dipoles, $\mu_{\mathrm{ag}}$ the transition dipole, $\tilde{\nu}_{\mathrm{ag}}$ the transition wavenumber, $h$ Planck's constant, $c_{0}$, the speed of light in vacuum, and $\tilde{\nu}$ the wavenumber of the optical field.

The ground state dipole $\mu_{z}$ can be determined from dielectric and refractive measurements for several concentrations according to the Guggenheim-Smith equation [29]

$\mu_{8}^{2}=\frac{27 k T \epsilon_{0} M_{2}}{N_{\mathrm{A}}} \frac{\alpha_{\epsilon}-\alpha_{n}}{\rho_{1}\left(\epsilon_{1}+2\right)^{21}}$

with $\alpha_{\xi}=\mathrm{d} \epsilon / \mathrm{d} w_{2}$ and $\alpha_{n}=\mathrm{d} n^{2} / \mathrm{d} w_{2}, \epsilon$ being the relative permittivity and $n$ the refractive index of the solution, $w_{2}$ and $M_{2}$ the mass fraction and the, molar mass of the solute, $p_{1}$ and $\epsilon_{1}$ the density and the relative permittivity of the pure (apolar) solvent, $k$ Boltzmann's constant, $T$ the temperature, $\epsilon_{0}$ the permittivity of free space, and $N_{\mathrm{A}}$ Avogadro's constant,

The transition dipole $\mu_{\text {ag }}$ can be determined by numerical integration of the absorption band [19,20]:

$\mu_{\text {as }}^{2}=\frac{3 h c_{0} \epsilon_{0} \ln 10}{2 \pi^{2} N_{\mathrm{A}}} \frac{9 n}{\left(n^{2}+2\right)^{2}} \int \frac{\kappa(\tilde{\nu})}{\tilde{\nu}} \mathrm{d} \tilde{\nu}$, 
wherein a Lorentz local field correction is included; $\kappa$ is the molar decadic extinction coefficient of the solute.

All methods of determination of excited state dipoles $\mu_{\mathrm{a}}$ are based on spectral shifts of the absorption band caused by an electric field, either external (electrochromism) or internal (solvatochromism) [1922]. Solvatochromism has been treated by many authors $[19,20,30]$. Most treatments are based on the Onsager model [31], according to which the molecule is considered as a point dipole in a spherical solvent cavity with radius $a$ and the solvent as a continuous dielectric body.

The general theory of solvatochromism [20] leads to expressions containing parameters which cannot be determined experimentally. Neglecting effects of polarizabilities and dispersion interactions on the solvent shift and assuming parallel ground and excited state dipoles one obtains the following equation [20]:

$$
\begin{gathered}
\tilde{\nu}_{\mathrm{abs}}^{\prime}=\tilde{\nu}_{\mathrm{abs}}+\frac{\left(\mu_{\mathrm{a}}-\mu_{\mathrm{g}}\right)^{2}}{4 \pi \epsilon_{0} a^{3} h c_{0}} \frac{n^{2}-1}{2 n^{2}+1} \\
=\tilde{\nu}_{0}-2 \frac{\mu_{\mathrm{g}}\left(\mu_{\mathrm{a}}-\mu_{\mathrm{g}}\right)}{4 \pi \epsilon_{0} a^{3} h c_{0}} \frac{\epsilon-1}{2 \epsilon+1}
\end{gathered}
$$

where $\tilde{\nu}_{\text {abs }}$ and $\tilde{\nu}_{0}$ are wavenumbers of the absorption maxima in solution and gasphase, respectively, and $\tilde{\nu}_{\mathrm{abs}}^{\prime}$ is a short notation for the left-hand side (lhs) of the equation. With given values for the ground state dipole $\mu_{\mathrm{z}}$ and the interaction radius $a$ and a set of $\tilde{\nu}_{\text {abs }}$ data obtained for different solvents eq. (5) can be solved iteratively for $\left(\mu_{\mathrm{a}}-\mu_{\mathrm{g}}\right)$ by linear regression against the permittivity function $(\epsilon-1) /(2 \epsilon+1)$. The poorly defined radius $a$ is the main source for the uncertainty of solvatochromically determined excited state dipoles. In the present work we try to reduce this problem adjusting the interaction radius by comparison with excited state dipoles obtained from electrooptical absorption measurements (vide infra).

In EOA measurements one determines the effect of an external electric field on the absorption of linearly polarized light by a dilute solution of an organic dye [22]. The EOA spectrum is given by

$$
L \kappa / \tilde{\nu}=\frac{\left(\kappa^{\mathrm{E}} / \tilde{\nu}\right)-(\kappa / \tilde{\nu})}{E_{0}^{2}}
$$

where $\kappa^{\mathrm{E}}$ is the extinction coefficient of the solute in presence of the applied field. A regression analysis of the EOA spectrum yields information on ground and excited state dipoles and polarizabilities of the solute molecules as well as the direction $\boldsymbol{m}$ of the transition dipole in the molecule-fixed frame. For molecules with large ground state dipoles and large changes of the dipole upon electronic excitation explicit polarizability contributions and terms due to the field dependence of the transition dipole can be neglected. In this case the essential experimental information is contained in three regression coefficients, $E, F$ and $G$, which we write for the purposes of this work in the form:

$$
\begin{aligned}
& E=\left(L_{0}^{2} / k^{2} T^{2}\right)\left[3\left(m \cdot \mu_{\mathrm{g}}\right)^{2}-\mu_{\mathrm{g}}^{2}\right], \\
& F=\left(L_{0}^{2} / k T\right) \mu_{\mathrm{g}} \cdot\left(\mu_{\mathrm{a}}-\mu_{\mathrm{g}}\right), \\
& G=\left(L_{0}^{2} / k T\right)\left(\boldsymbol{m} \cdot \mu_{\mathrm{g}}\right)\left[\boldsymbol{m} \cdot\left(\mu_{\mathrm{a}}-\mu_{\mathrm{g}}\right)\right],
\end{aligned}
$$

where $L_{0}=\left(\epsilon_{0}+2\right) / 3$ is the Lorentz local field factor for the static external field. In general Onsager local field factors are more appropriate [22]. Their application in the present work is not possible because of insufficient knowledge on the polarizability tensor of the investigated molecules.

With $\mu_{\mathrm{ga}}^{2}$ determined from the absorption spectrum using eq. (4) and $\left(\mu_{\mathrm{a}}-\mu_{\mathrm{g}}\right)$ obtained from either solvatochromism or electrochromism it is possible to estimate the CT contribution to the second-order polarizability according to eq. (1). In this approach one chooses the wavenumber of the band maximum for $\tilde{\nu}_{\text {ag }}$. However, electronic bands of organic molecules in liquid solution consist of several vibronic transitions and may be broad and strongly structured. In this case it is more satisfactory to combine eqs. (1), (2) and (4) into

$$
\begin{array}{r}
\beta_{\mathrm{CT}}(\tilde{\nu})=\frac{9 \epsilon_{\mathrm{o}} \ln 10}{4 \pi^{2} h c_{0} N_{\mathrm{A}}}\left(\mu_{\mathrm{a}}-\mu_{\mathrm{g}}\right) \frac{9 n}{\left(n^{2}+2\right)^{2}} \\
\times \int \frac{\kappa\left(\tilde{\nu}_{\mathrm{ag}}\right)}{\tilde{\nu}_{\mathrm{ag}}} \frac{\tilde{\nu}_{\mathrm{ag}}^{2}}{\left(\tilde{\nu}_{\mathrm{ag}}^{2}-\tilde{\nu}^{2}\right)\left(\tilde{\nu}_{\mathrm{ag}}^{2}-4 \tilde{\nu}^{2}\right)} \mathrm{d} \tilde{\nu}_{\mathrm{ag}},
\end{array}
$$

where the integration is over the whole range of wavenumbers of the electronic band. It is assumed that the wavenumber $\tilde{\nu}$ lies in the preresonance regime where $\beta(\tilde{\nu})$ is a real quantity. With eq. (10) the dispersive enhancement of $\beta$ is calculated with a correct spectral weighting since the experimentally de- 
termined extinction coefficient $\kappa$ ensures that the intensity profile (Franck-Condon progression) of the electronic band and the spectral broadening is properly taken into account.

In the EFISH experiment one utilizes a static external electric field $E_{0}$ to induce a second-order nonlinearity $d=\Gamma E_{0}$ in a liquid solution. The nonlinearity $d$ is usually determined by non-phase-matched second harmonic generation applying the wedge technique [18]. For the molecules investigated in this work it is justified to assume Kleinman symmetry of the second-order polarizability tensor $\boldsymbol{\beta}(-2 \omega ; \omega, \omega)$ and to neglect the dependence of $\beta$ on the applied field $\gamma(-2 \omega ; \omega, \omega, 0)$. With these approximations one obtains the following equation for the experimental determination of the second-order polarizability:

$$
\begin{aligned}
& L_{2 \omega} L_{\omega}^{2} L_{0}\left(\frac{\mu_{\mathrm{g}} \cdot \beta}{5 k T}\right) \\
& \quad=\frac{\epsilon_{0} M_{2}}{\rho_{1} N_{\mathrm{A}}}\left[\frac{\partial \Gamma}{\partial w_{2}}-\Gamma_{1}\left(\frac{1}{3 L_{2 \omega}} \frac{\partial \epsilon_{2 \omega}}{\partial w_{2}}\right.\right. \\
& \left.\left.+\frac{2}{3 L_{\omega}} \frac{\partial \epsilon_{\omega}}{\partial w_{2}}+\frac{1}{3 L_{0}} \frac{\partial \epsilon_{0}}{\partial w_{2}}+\frac{1}{\rho_{1}} \frac{\partial \rho}{\partial w_{2}}-1\right)\right]
\end{aligned}
$$

where $L_{\Omega}=\left(\epsilon_{\Omega}+2\right) / 3, \Omega=0, \omega, 2 \omega$, are Lorentz factors at the indicated field frequencies and $\beta_{i}=\sum_{k} \beta_{i k k}$ are components of the vector part $\beta$ of the secondorder polarizability. The terms in parenthesis correct for the dependence of the local field factors and of the density on the constitution of the phase; $\partial \rho / \partial w_{2}$ was neglected in the present work. A more general formulation of eq. (11) in terms of partial molar quantities will be given elsewhere [25].

\section{Results and discussion}

\subsection{Evaluation}

Fig. 1 shows the optical $(\kappa / \tilde{\nu})$ and electrooptical $(L \kappa / \tilde{\nu})$ spectrum of $\mathrm{Me}_{2} \mathrm{NT}_{2} \mathrm{NO}_{2}$ in the region of the first allowed singlet excitation. The usual regression analysis [22] yields the EOA coefficients $E=(15030 \pm 270) \times 10^{-20} \mathrm{~m}^{2} \mathrm{~V}^{-2}, F=(5285 \pm 140)$ $\times 10^{-40} \mathrm{CV}^{-1} \mathrm{~m}^{2}$ and $G=(5250 \pm 140) \times 10^{-40} \mathrm{C}$ $\mathrm{V}^{-1} \mathrm{~m}^{2}$. With eqs. (7) $-(9)$ it follows $\mu_{\mathbf{8}}=$ $(26.7 \pm 0.3) \times 10^{-30} \mathrm{C} \mathrm{m}$ and $\mu_{\mathrm{a}}=(73 \pm 2) \times 10^{-30}$
$\mathrm{C} \mathrm{m}$. From the equality of $F$ and $G$, eqs. (8) and (9), it can be concluded that the dipole moments of the contributing excited vibronic states remain constant over the whole absorption band [22]. Therefore the excellent agreement of the experimental and approximated EOA spectrum suggests that there is only one intense electronic transition contributing in this spectral region.

The solvatochromism of $\mathrm{Me}_{2} \mathrm{NT}_{2} \mathrm{NO}_{2}$ is shown in fig. 2 where the lhs of eq. (5) is plotted versus the permittivity function. A linear regression was performed for the solvent shifts represented by full points in fig. 2. The corresponding solvents have little or no specific type of interaction with the solute different from electrostatic dipole-dipole forces. Eq. (5) yields an excited state dipole which is in agreement with the EOA value (vide supra) setting $a=0.69 L$ where $L$ is the radius of the smallest sphere enclosing the molecule. This choice of the interaction radius and the same set of solvents was equally applied to all other oligothiophenes studied in this work.

As seen in table 3, the agreement between data from EFISH measurements and the solvatochromic method is excellent for all thiophene oligomers compared.

For $\mathrm{Me}_{2} \mathrm{NT}_{2} \mathrm{NO}_{2}$ the dispersion enhancement in the EFISH experiment seems to be somewhat underestimated by the two-level model (eq. (1)). Much better agreement can be obtained using eq. (10), where the dispersive enhancement is treated more exactly through integration over the whole absorption band. From the excellent agreement of both methods it can be concluded that the main contribution of the second-order polarizability arises from the low-lying charge transfer transition as it was supposed by the two-level model.

\subsection{Comparison of bithiophenes with biphenyls and stilbenes}

From the results given in tables 1 and 3 it is possible to compare the second harmonic generation efficiency of donor and acceptor groups in the bithiophene system. The efficiency of the donors increases in the order $\mathrm{H}, \mathrm{MeO}, \mathrm{MeS}, \mathrm{Me}_{2} \mathrm{~N}, \mathrm{PyN}$. Nitro was found to be a more efficient acceptor than formyl in good agreement with results given for other $\pi$ systems. With regard to the general observable correla- 


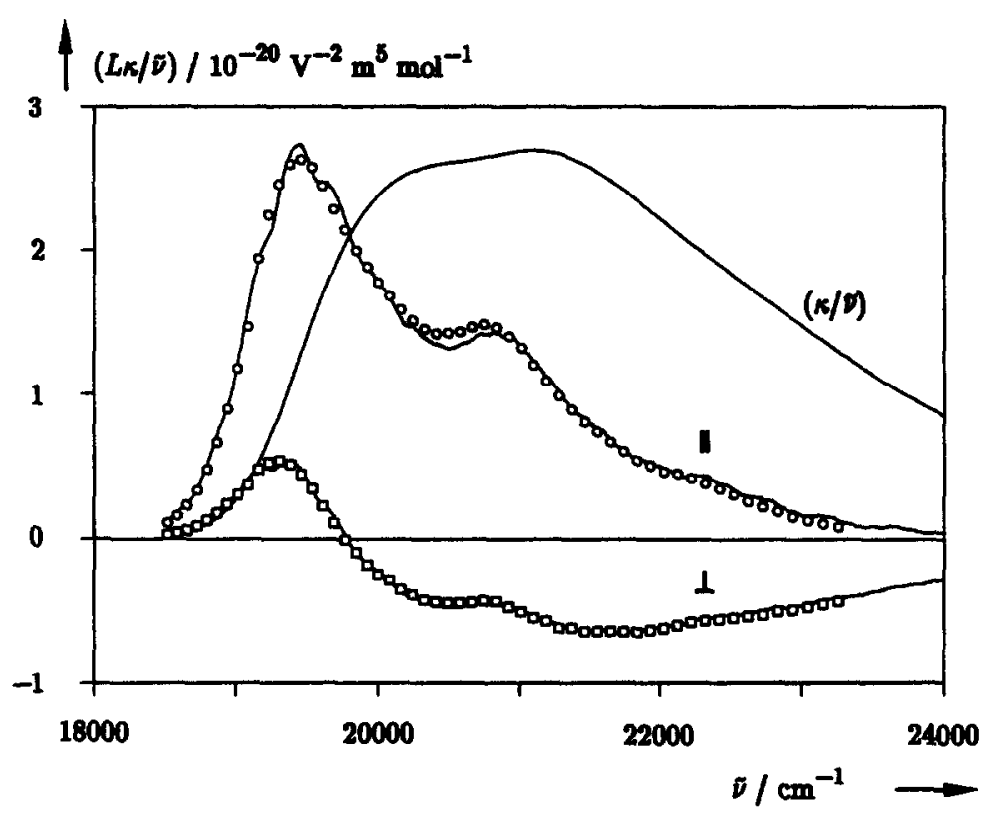

Fig. 1. Electrooptical absorption spectrum $(L \kappa / \tilde{\nu})$ of $\mathrm{Me}_{2} \mathrm{NT}_{2} \mathrm{NO}_{2}$. The figure shows experimental data points for parallel $(\|)$ and perpendicular $(\perp)$ polarization of the incident light relative to the applied field and calculated curves obtained by a general linear least squares optimization. The definition of $(L \kappa / \tilde{\nu})$ is given in eq. (6). The absorption spectrum $(\kappa / \tilde{\nu})$ is displayed in arbitrary units. Solvent: cyclohexane, $T=298 \mathrm{~K}$.

tion between $\beta_{0}$ and $\lambda_{\max }$ (see eq. (2)) it is interesting to note that $\mathrm{MeOT}_{2} \mathrm{NO}_{2}$ has a lower value for $\beta_{0}$ than $\mathrm{MeST}_{2} \mathrm{NO}_{2}$ despite of a longer wavelength absorbance. On the basis of the two-level model this can be explained from the much higher excited state dipole moment of $\mathrm{MeST}_{2} \mathrm{NO}_{2}$. Obviously for electronrich heteroaromatics like thiophene the efficiency of rather weak donors like methoxy is diminished.

In table 4 static second-order polarizabilities of bithiophenes, biphenyls and stilbenes are summarized. For bithiophenes we have used our own EFISH data, for biphenyls and stilbenes we have used the EFISH data given by Cheng at $1910 \mathrm{~nm}[13,14]$. The static coefficients are calculated by deviding the measured value by the relevant dispersion factor according to eq. (1). Because of the good agreement between our results for 4-dimethylamino-4' -nitrobiphenyl with the data given by Cheng, such a comparison seems reasonable. According to the two-level model solvents of greater polarity used by Cheng are expected to give somewhat higher values for $\beta$.

The results from table 4 suggest that bithiophenes exhibit much greater second-order polarizabilities than biphenyls and nearly as great values as stilbenes, which are longer by one double bond. The high efficiency of bithiophenes for second harmonic generation is rationalized by the following reasons: (i) The reduction in CT transition energy according to the bathochromic effect of sulfur and to the partial elimination of the aromatic character in heteroaromatics. This reduced aromaticity favors quinonoid polyenelike structures and consequently better interaction of the end groups. (ii) The enhanced $\pi$ overlap between thiophene units in comparison to phenylene units. In biphenyls the $\pi$ overlap is reduced because of the steric interactions of the ortho-hydrogen atoms, whereas for $\alpha$-bithiophenes hydrogens do not have any steric interaction in a coplanar trans-conformation (scheme 2).

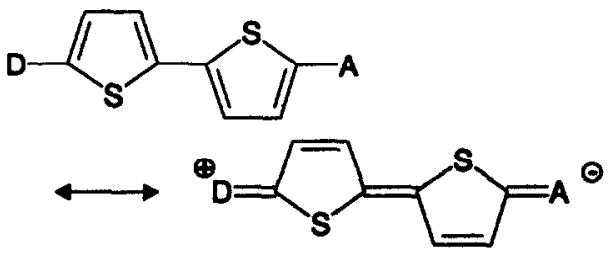

Scheme 2. 


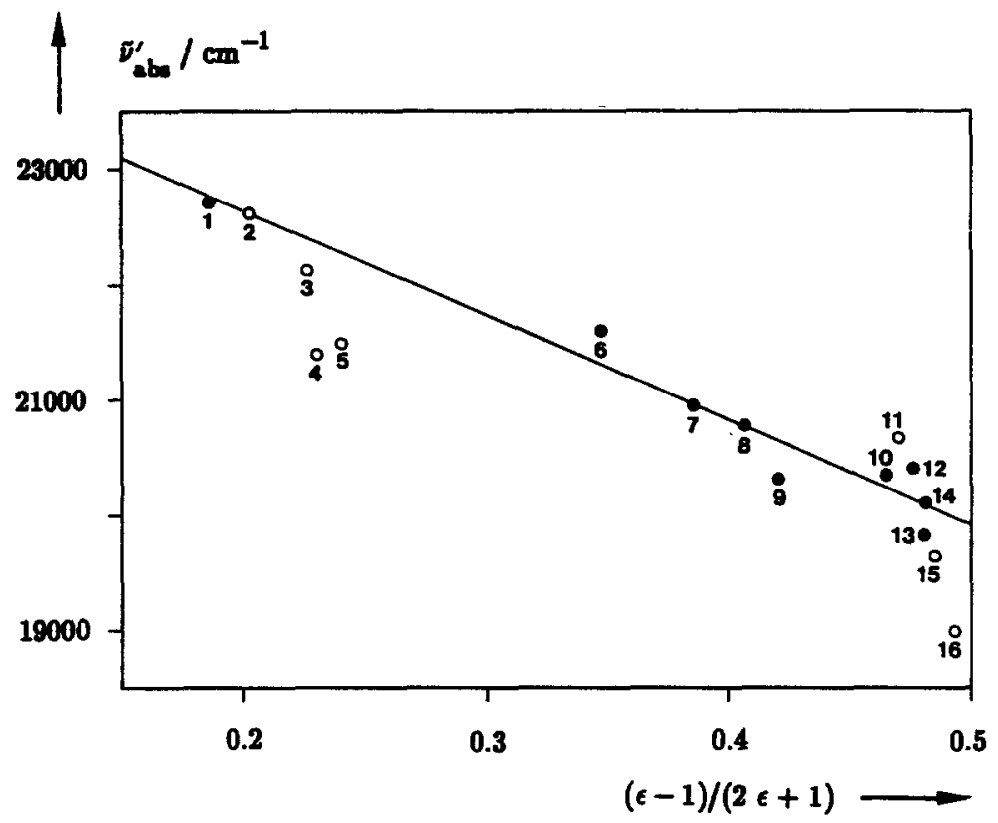

Fig. 2. Solvatochromism of $\mathrm{Me}_{2} \mathrm{NT}_{2} \mathrm{NO}_{2}$. Solvents: (1) hexane, (2) cyclohexane, (3) tetrachloromethane, (4) benzene, (5) toluene, (6) diethyl ether, (7) ethyl acetate, (8) tetrahydrofurane, (9) dichloromethane, (10) acetone, (11) ethanol, (12) methanol, (13) dimethylformamide, (14) acetonitrile, (15) dimethylsulfoxide, (16) formamide. The linear regression was made for the solvents represented by full points. The definition of $\tilde{\nu}_{a b}^{\prime}$ is given in eq. (5).

Table 1

Dipole moments, absorption data and static second-order polarizabilities $\left(\beta_{\mathrm{CT}}\right)$ from solvatochromism of $2,2^{\prime}$-bithiophenes

\begin{tabular}{|c|c|c|c|c|c|c|c|c|}
\hline D & $\mathbf{A}$ & $\begin{array}{l}\mu_{\mathrm{m}}{ }^{m)} \\
\left(10^{-30} \mathrm{Cm}\right)\end{array}$ & ${ }^{a}\left(10^{-10} \mathrm{~m}\right)$ & ${ }^{\mu_{2}}\left(10^{-30} \mathrm{Cm}\right)$ & $\begin{array}{l}\left.\lambda_{\max } \mathrm{b}\right) \\
\left(10^{-9} \mathrm{~m}\right)\end{array}$ & $\begin{array}{l}\kappa_{\operatorname{tanx}}^{b)} \\
\left(m^{2} \mathrm{~mol}^{-1}\right)\end{array}$ & $\begin{array}{l}\mu_{m}^{b)} \\
\left(10^{-30} \mathrm{Cm}\right)\end{array}$ & $\begin{array}{l}\beta_{0}{ }^{c)} \\
\left(10^{-50} \mathrm{C} \mathrm{m}^{3} \mathrm{~V}^{-2}\right)\end{array}$ \\
\hline $\mathbf{H}$ & $\mathrm{NO}_{2}$ & 16.8 & 4.19 & 42 & 375 & 1750 & 16.2 & 3.5 \\
\hline $\mathrm{MeO}$ & $\mathrm{NO}_{2}$ & 20.1 & 4.92 & 58 & 408 & 1930 & 17.0 & 7.0 \\
\hline MeS & $\mathrm{NO}_{2}$ & 16.6 & 5.08 & 71 & 391 & 1830 & 17.8 & 10.0 \\
\hline $\mathrm{Me}_{2} \mathrm{~N}$ & $\mathrm{NO}_{2}$ & 26.5 & 4.95 & $73(73)^{d)}$ & 466 & 2500 & 20.0 & 15.2 \\
\hline PyN & $\mathbf{N O}_{2}$ & 28.1 & 5.48 & 83 & $499(477)^{e)}$ & 2700 & 19.9 & $20.8(19.0)^{e)}$ \\
\hline $\mathrm{MeO}$ & $\mathrm{CHO}$ & 15.4 & 4.92 & 40 & 372 & 2270 & 17.6 & 4.0 \\
\hline $\mathrm{Me}_{2} \mathbf{N}$ & $\mathrm{CHO}$ & 19.7 & 4.95 & 57 & 421 & 2750 & 19.3 & 9.3 \\
\hline PyN & $\mathrm{CHO}$ & 21.7 & 5.48 & 59 & 440 & 3310 & 20.5 & 11.4 \\
\hline $\mathrm{Me}_{2} \mathrm{NB}_{2} \mathrm{NO}_{2}$ & & 22.4 & 5.20 & $72(80)^{d)(s)}$ & 375 & 2000 & 18.2 & 8.8 \\
\hline
\end{tabular}

a) In benzene, experimental errors $\pm 0.2 \times 10^{-30} \mathrm{C} \mathrm{m}\left(10^{-30} \mathrm{C} \mathrm{m}=0.2998 \mathrm{D}\right)$. b) In $n$-hexane.

c) According to eq. (2), in $10^{-50} \mathrm{C} \mathrm{m}^{3} \mathrm{~V}^{-2}\left(=2.6944 \times 10^{-30} \mathrm{esu}\right)$. d) Electrooptical value.

c) Structure. ") 4-Dimethylamino-4'-nitro-biphenyl. ") Ref. [22].

An interesting aspect for applications arises from the large values of ground state dipole moments. For the case of electric-field poled polymers $\mu_{g} \cdot \boldsymbol{\beta}$ has to be optimized instead of $\beta[10]$. This quantity seems to be even larger for bithiophenes than for stilbenes.

\subsection{Effect of conjugation length}

From the above reasons long-chain oligothiophenes are expected to have much greater second-order polarizabilities than bithiophenes. So we have 
Table 2

Dipole moments, absorption data and static second-order polarizabilities $\left(\beta_{\mathrm{CT}}\right)$ from solvatochromism of oligothiophenes

\begin{tabular}{|c|c|c|c|c|c|c|c|}
\hline $\mathrm{DT}_{n} \mathrm{~A}$ & $\begin{array}{l}\left.\mu_{8}\right) \\
\left(10^{-30} \mathrm{C} \mathrm{m}\right)\end{array}$ & $a^{\left(10^{-10} \mathrm{~m}\right)}$ & $\begin{array}{l}\mu_{\mathrm{a}} \\
\left(10^{-30} \mathrm{C} \mathrm{m}\right)\end{array}$ & $\begin{array}{l}\left.\lambda_{\max } \mathrm{b}\right) \\
\left(10^{-9} \mathrm{~m}\right)\end{array}$ & $\begin{array}{l}\kappa_{\max }^{b)} \\
\left(m^{2} \mathrm{~mol}^{-1}\right)\end{array}$ & $\begin{array}{l}\mu_{u^{b}}^{b)} \\
\left(10^{-30} \mathrm{C} \mathrm{m}\right)\end{array}$ & $\begin{array}{l}\beta_{0}{ }^{())} \\
\left(10^{-50} \mathrm{C} \mathrm{m}^{3} \mathrm{~V}^{-2}\right)\end{array}$ \\
\hline $\mathrm{MeOT}_{1} \mathrm{NO}_{2}$ & 18.2 & 3.58 & 39 & 340 & 1180 & 12.4 & 1.4 \\
\hline $\mathrm{MeOT}_{2} \mathrm{NO}_{2}$ & 20.1 & 4.92 & 58 & 408 & 1930 & 17.0 & 7.0 \\
\hline $\mathrm{MeOT}_{3} \mathrm{NO}_{2}$ & 20.1 & 6.23 & 68 & 442 & 2500 & 20.5 & 15.0 \\
\hline $\mathrm{MeOT}_{4} \mathrm{NO}_{2}$ & 20 & 7.60 & 92 & 454 & $2950^{d)}$ & $24.2^{\text {d) }}$ & 33.0 \\
\hline $\mathrm{PyNT}_{2} \mathrm{NO}_{2}$ & 28.1 & 5.48 & 83 & $499(477)^{c)}$ & 2700 & 19.9 & $20.8(19.0)^{c)}$ \\
\hline $\mathrm{PyNT}_{3} \mathrm{NO}_{2}$ & 28 & 6.83 & 97 & 505 & $2360^{d)}$ & $23.1^{\text {d) }}$ & 35.2 \\
\hline
\end{tabular}

a) In benzene. b) In $n$-hexane. c) According to eq. (2), d) In dichloromethane. e) Structure.

Table 3

Second-order polarizabilities $\left(\beta_{z}\right)$ of oligothiophenes and biphenyls measured by EFISH at $1064 \mathrm{~nm}$

\begin{tabular}{|c|c|c|c|c|c|c|c|}
\hline \multirow[t]{2}{*}{$\mathrm{DT}_{n} \mathrm{~A}$} & \multirow[t]{2}{*}{ Solvent } & \multirow{2}{*}{$\lambda_{\max }\left(10^{-9} \mathrm{~m}\right)$} & \multirow{2}{*}{$\begin{array}{l}\mathrm{d} \Gamma / \mathrm{d} w_{2} \\
\left(10^{-20} \mathrm{~m}^{2} \mathrm{v}^{-2}\right)\end{array}$} & \multirow{2}{*}{$\begin{array}{l}\left.\beta_{1064 \mathrm{~nm}} \mathrm{c}\right) \\
\left(10^{-30} \mathrm{C} \mathrm{m}^{3} \mathrm{~V}^{-2}\right)\end{array}$} & \multirow{2}{*}{$\begin{array}{l}\beta_{0}{ }^{d)} \\
\left(10^{-30} \mathrm{C} \mathrm{m}^{3} \mathrm{~V}^{-2}\right)\end{array}$} & \multicolumn{2}{|c|}{ Solvatochromism $\left(\beta_{\mathrm{CT}}\right)$} \\
\hline & & & & & & $\begin{array}{l}\beta_{1064 \mathrm{~nm}}{ }^{e)} \\
\left(10^{-50} \mathrm{C} \mathrm{m}^{3} \mathrm{~V}^{-2}\right)\end{array}$ & $\begin{array}{l}\left.\beta_{1064 \mathrm{~nm}} \mathrm{f}\right) \\
\left(10^{-50} \mathrm{C} \mathrm{m}^{3} \mathrm{~V}^{-2}\right)\end{array}$ \\
\hline $\mathrm{HT}_{2} \mathrm{NO}_{2}$ & $\mathrm{MCH}^{*}$ & 378 & 4.8 & 6.9 & 3.0 & 8.2 & 8.1 \\
\hline $\mathrm{MeOT}_{2} \mathrm{NO}_{2}$ & $\mathrm{MCH}$ & 411 & 10.8 & 15 & 5.2 & 20 & 20 \\
\hline $\mathrm{MeST}_{2} \mathrm{NO}_{2}$ & MCH & 394 & 9.8 & 18 & 7.0 & 25 & 27 \\
\hline $\mathrm{Me}_{2} \mathrm{NT}_{2} \mathrm{NO}_{2}$ & MCH & 472 & 103.0 & 118 & 20.1 & 91 & 112 \\
\hline $\mathrm{MeOT}_{1} \mathrm{NO}_{2}$ & $\mathrm{CCl}_{4}$ & 349 & 6.7 & 2.8 & 1.4 & 2.0 & 1.9 \\
\hline $\mathrm{MeOT}_{2} \mathrm{NO}_{2}$ & $\mathrm{CCl}_{4}$ & 418 & 29.1 & 17 & 5.6 & 22 & 21 \\
\hline $\mathrm{MeOT}_{3} \mathrm{NO}_{2}$ & $\mathrm{CCl}_{4}$ & 452 & 74.0 & 60 & 13.7 & 67 & 81 \\
\hline $\mathrm{Hex}_{2} \mathrm{NB}_{2} \mathrm{NO}_{2}{ }^{\text {b) }}$ & MCH & 401 & 15.1 & 27 & 10.2 & - & - \\
\hline $\mathrm{Me}_{2} \mathrm{NB}_{2} \mathrm{NO}_{2}$ & toluene & 400 & 35.6 & 33 & 12.2 & - & - \\
\hline
\end{tabular}

a) Methylcyclohexane.

b) 4 -Di- $n$-hexylamino-4' -nitro-biphenyl, $\mu_{2}=24.9 \times 10^{-30} \mathrm{C} \mathrm{m}$.

c) Experimental value, errors 5-10\%.

d) Static second-order polarizability calculated from the experimental value using eq. (1).

e) Two-state contribution to the second-order polarizability at $1064 \mathrm{~nm}$ estimated according to eqs. (1) and (2). $\mu_{\text {ag }}$ was determined from the absorption spectrum in the given solvent using eq. (4).

f) Two-state contribution to the second-order polarizability at $1064 \mathrm{~nm}$ estimated according to eq. (10) from the absorption spectrum in the given solvent. $\mu_{\mathrm{z}}$ and $\mu_{\mathrm{a}}$ are listed in tables 1 and 2 .

Table 4

Comparison of static second-order polarizability $\left(\beta_{0}\right)$ of biphenyls (1), bithiophenes (2) and stilbenes (3) (EFISH data) *)

\begin{tabular}{|c|c|c|c|c|}
\hline D & $\mathbf{A}$ & in 1,4-dioxane ${ }^{b)}$ & $\underbrace{}_{\text {in } \mathrm{MCH}^{\mathrm{c}}}$ & in 1,4-dioxane $^{\text {b) }}$ \\
\hline $\begin{array}{l}\mathrm{H} \\
\mathrm{MeO} \\
\mathrm{MeS} \\
\mathrm{Me}_{2} \mathrm{~N}\end{array}$ & $\begin{array}{l}\mathrm{NO}_{2} \\
\mathrm{NO}_{2} \\
\mathrm{NO}_{2} \\
\mathrm{NO}_{2}\end{array}$ & $\begin{array}{c}1.3 \\
2.9 \\
- \\
14.8^{d)}\end{array}$ & $\begin{array}{r}3.0 \\
5.2 \\
7.0 \\
20.1\end{array}$ & $\begin{array}{c}3.4 \\
8.6 \\
7.9 \\
20.6^{d)}\end{array}$ \\
\hline
\end{tabular}

a) Calculated from the experimental value using eq. (1), in $10^{-50} \mathrm{C} \mathrm{m}^{3} \mathrm{~V}^{-2}\left(=2.6944 \times 10^{-30} \mathrm{esu}\right)$.

b) Refs. [13,14]: c) $\mathrm{MCH}=$ methylcyclohexane. ") In chloroform. 


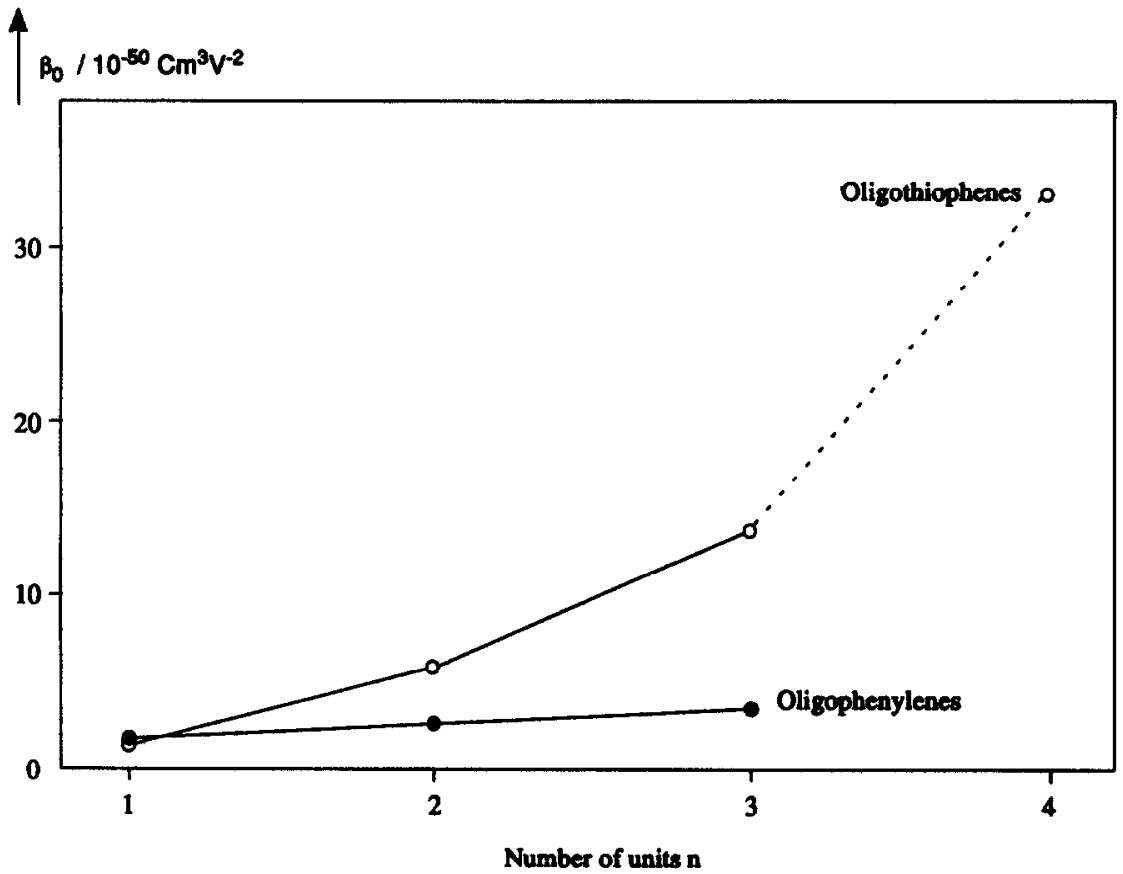

Fig. 3. Effect of increasing chain length $n$ on the static second-order polarizability $\beta_{0}$ of $\mathrm{MeOT}_{n} \mathrm{NO}_{2}$ in comparison to $\mathrm{MeOB}{ }_{n} \mathrm{NO}_{2}[14$ ] The data point for oligothiophenes $(n=4)$ was obtained from solvatochromism.

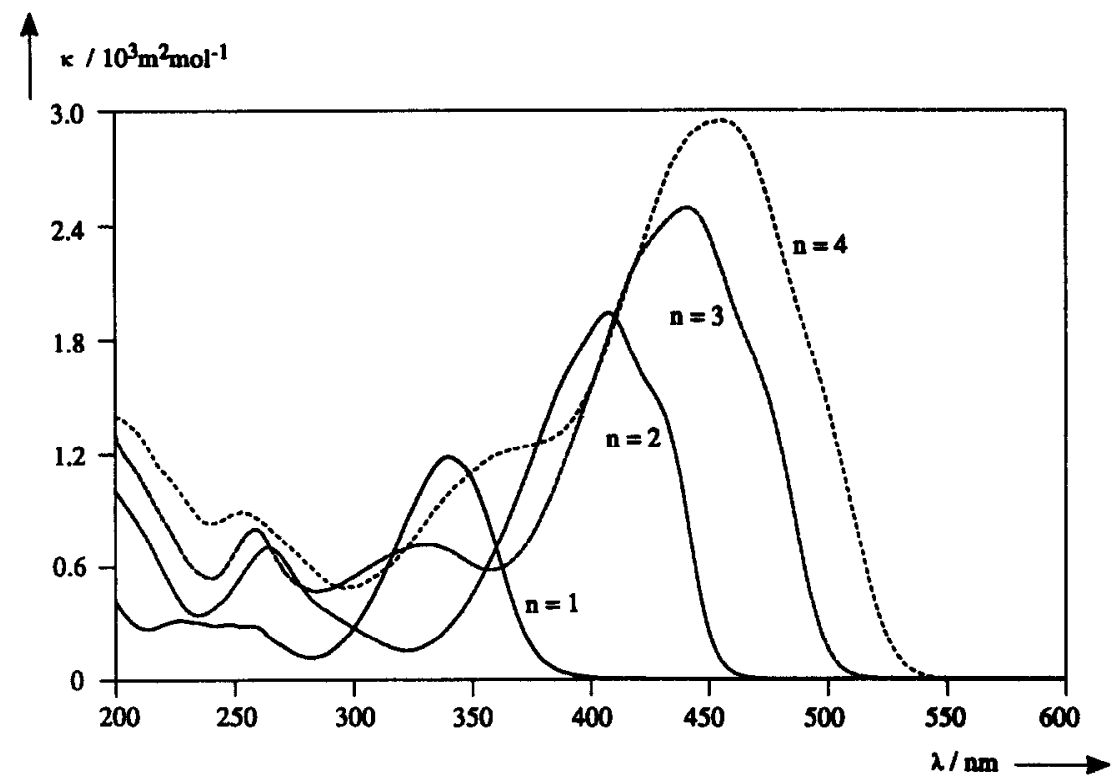

Fig. 4. UV/vis absorption spectra of $\mathrm{MeOT}_{n} \mathrm{NO}_{2}$ in $n$-hexane solution. $\boldsymbol{\kappa}$ is the molar decadic extinction coefficient. 
studied the dependence of $\beta_{0}$ on the number of repeat units, $n$, for methoxy-nitro substituted thiophene oligomers with $n=1-4$ (fig. 3 ). For the methoxy and nitro end groups experimental data on chain dependence are also available for diphenylpolyenes and oligophenylenes $[12,14]$. Whereas for diphenylpolyenes no saturation of $\beta_{0}$ is observed for up to 9 double bonds, in oligophenylenes $\beta_{0}$ maximizes between bi- and terphenyls, which was explained by constraints on $\pi$ overlap and the high degree of aromatization of the phenyl unit [14]. In fig. 3 our results on chain dependence for oligothiophenes are compared to oligophenylenes.

For up to 8 double bonds no saturation of $\beta_{0}$ is observed for thiophene oligomers. Like polyenes oligothiophenes show a substantial increase of $\beta_{0}$ with the number of double bonds. From logarithmic plots of $\beta_{0}$ versus $n$ we get for $\mathrm{MeOT}_{n} \mathrm{NO}_{2} \beta_{0} \sim n^{2.1}$ (EFISH, $n=1-3$ ), $\beta_{0} \sim n^{2.2}$ (solvatochromism, $n=1-4$ ). For

Similar trends are also found for the maximum absorption wavelengths $\lambda_{\max }$ as as function of conjugation units $n$ (fig. 4).

Whereas CT transitions of oligothiophenes like polyenes bathochromically shift with increasing chain length, in oligophenylenes absorption wavelength maximizes again for bi- or terphenyls [ $14,15,32]$. In summary our results on chain dependence prove oligothiophenes to be excellent conjugation units allowing intense interactions of the end groups.

\section{Conclusion}

We have studied second-order polarizabilities of a new series of interesting nonlinear optical organic molecules applying the EFISH technique, solvatochromism and electrooptical absorption measurements.

The superiority of the thiophene unit over the phenyl unit was demonstrated, since thiophenes exhibit greater efficiencies per unit molecular volume than systems containing the phenyl unit.

The results on chain length dependence suggest that oligothiophenes are much more comparable to polyenes than to oligophenylenes with regard to their optical and nonlinear optical properties.

Because of the favorable interaction of large second-order polarizabilities and dipole moments do- nor-acceptor substituted oligothiophenes are recommended as interesting candidates for applications in poled polymers.

\section{Acknowledgement}

This work was generously supported by the Deutsche Forschungsgemeinschaft (SFB 329 and project Wo 402/2-1). We thank Professor W. Liptay for helpful discussions and his evaluation program for solvatochromic measurements.

\section{References}

[1] D.D.C. Bradley, Chem. Britain 27 (1991) 719.

[2] J. Simon, J.-J. André and A. Skoulios, Nouv. J. Chim. 10 (1986) 295.

[3] F. Effenberger, H. Schlosser, P. Bäuerle, S. Maier, H. Port and H.C. Wolf, Angew. Chem. Intern. Ed. 27 (1988) 281; F. Effenberger and H.C. Wolf, New J. Chem. 15 (1991) 117; C. Bubeck, F. Effenberger, L. Häussling, D. Neher, C.-P. Niesert and H. Ringsdorf, Advan. Mater. 4 (1992) 413.

[4] M. Blanchard-Desce, I. Ledoux, J.-M. Lehn and J. Malthête, J. Zyss, J. Chem. Soc. Chem. Commun. (1988) 737; M. Barzoukas, M. Blanchard-Desce, D. Josse, J.-M. Lehn and J. Zyss, Chem. Phys. 133 (1989) 323.

[5] D. Fichou, B. Xu, G. Horowitz and F. Garnier, Synth. Metals 41 (1991) 463;

P. Bäuerle, Advan. Mater, 4 (1992) 102.

[6] M.-T. Zhao, M. Samoc, B.P. Singh and P.N. Prasad, J. Phys. Chem. 93 (1989) 7916;

H. Thienpont, G.L.J.A. Rikken, E.W. Meijer, W. ten Hoeve and H. Wynberg, Phys. Rev. Letters 65 (1990) 2141.

[7] J. Roncali, Chem. Rev. 92 (1992) 711.

[8] B. Xu, D. Fichou, G. Horowitz and F. Garnier, Advan. Mater. 3 (1991) 150;

F. Garnier, G. Horowitz, X. Peng and D. Fichou, Advan. Mater. 2 (1990) 592.

[9] D.J. Williams, Angew. Chem. Intern. Ed. 23 (1984) 690; J. Simon, P. Bassoul and S. Norvez, New J. Chem. 13 (1989) 13.

[10] A. Buckley, Advan. Mater. 4 (1992) 153.

[11] A. Dulcic, C. Flytzanis, C.L. Tang, D. Pépin, M. Fétizon and Y. Hoppilliard, J. Chem. Phys. 74 (1981) 1559.

[12] R.A. Huijts and G.L.J. Hesselink, Chem. Phys. Letters 156 (1989) 209.

[13] L.-T. Cheng, W. Tam, S.H. Stevenson, G.R. Meredith, G. Rikken and S.R. Marder, J. Phys. Chem. 95 (1991) 10631.

[14] L.-T. Cheng, W. Tam, S.R. Marder, A.E. Stiegman, G. Rikken and C.W. Spangler, J. Phys. Chem. 95 (1991) 10643.

[15] I. Ledoux, J. Zyss, A. Jutand and C. Amatore, Chem. Phys. 150 (1991) 117. 
[16] G. Mignani, F. Leising, R. Meyrueix and H. Samson, Tetrahedron Letters 31 (1990) 4743;

F. Leising, R. Meyrueix and G. Mignani, Eur. Pat. Appl. EP 384.811 (Cl. C07D333/24), 29 Aug. 1990, FR. Appl. 89/ 2.271, 22 Feb. 1989, Chem. Abstr. 114 (1991) 81568p.

[17] F. Würthner, Dissertation, University of Stuttgart (presumably 1993).

[18] B.F. Levine and C.G. Bethea, J. Chem. Phys. 63 (1975) 2666;

K.D. Singer and A.F. Garito, J. Chem. Phys. 75 (1981) 3572.

[19] W. Liptay, Angew. Chem. Intern. Ed. 8 (1969) 177.

[20.] W. Liptay, Z. Naturforsch. 20a (1965) 1441.

[21] W. Liptay and J. Czekalla, Z. Elektrochem. 65 (1961) 721.

[22] W. Liptay, in: Excited states, Vol. 1, ed. C. Lim (Academic Press, New York, 1974) p. 129.

[23] J.L. Oudar and D.S. Chemla, J. Chem. Phys. 66 (1977) 2664;

M.S. Paley, J.M. Harris, H. Looser, J.C. Baumert, G.C. Bjorklund, D. Jundt and R.J. Twieg, J. Org. Chem. 54 (1989) 3774.
[24] J. Sicé, J. Am. Chem. Soc. 75 (1953) 3697.

[25] R. Wortmann, P. Krämer, C. Glania, S. Lebus and N. Detzer, Chem. Phys. 173 (1993) 99.

[26] Landolt-Börnstein, Vol. III/11 (Springer, Berlin, 1979) p. 671

[27] W. Baumann, Ber. Bunsenges. Physik. Chem. 80 (1976) 231.

[28] D. Pugh and J.O. Morley, in: Nonlinear optical properties of organic molecules and crystals, Vol. 1, eds. D.S. Chemla and J. Zyss (Academic Press, New York, 1987) p. 206.

[29] F. Moll and E. Lippert, Z. Elektrochem. 58 (1954) 853; J. Czekalla, Z. Elektrochem. 60 (1956) 145.

[30] Y. Ooshika, J. Phys. Soc. Japan 9 (1954) 594;

E.G. McRae, J. Phys. Chem. 61 (1957) 562;

E. Lippert, Z. Elektrochem. 61 (1957) 962;

N.G. Bakhshiev, M.I. Knyazhanskii, V.I. Minkin, O.A. Osipov and G.V. Saidov, Russian Chem. Rev. 38 (1969) 740.

[31] L. Onsager, J. Am. Chem. Soc. 58 (1936) 1486.

[32] R.W.H. Berry, P. Brocklehurst and A. Burawoy, Tetrahedron $10(1960) 109$. 